\title{
THE IDENTIFICATION OF ARTIFICIAL COLORATION IN DIAMOND
}

\author{
By Kenneth V. G. Scarratt
}

Since Robert Crowningshield's discovery in the late 1950s that diamonds that have been artificially colored by irradiation and subsequent annealing could be identified by their characteristic absorption spectra (in particular, the band at 595 (592) nm, much more information has become available about the radiation-related bands seen in the visible spectra of diamonds. The introduction of cryogenics has made the observation by hand spectroscope or the recording by spectrophotometer of a diamond's visible spectrum less troublesome. But it has also opened the eyes of the gemologist to the fact that. virtually any band that can be artificially induced in the spectrum of diamond by irradiation and subsequent annealing can also occur naturally. This makes identification of the source of color in some diamonds, particularly fluorescent green and some yellow stones, very difficult.

\section{ABOUT THE AUTHOR}

Mr. Scarratt is director of the Gem Testing Laboratory of the London Chamber of Commerce and Industry, London, England.

The author gratefully acknowledges the generosity of Dr. Alan T. Collins in allowing the use of the illustrations in figures 4 and 8 , and his help in producing figures 6 and 11 .

This article was developed from a paper presented at the International Gemological Symposium in Los Angeles, California, February 1982

1982 Gemological Institute of America
$\mathrm{D}$ iamond combines a magnificent brilliance and durability with a wealth of differing colors, characteristics that make it unique among gemstones. Recently, diamonds with a definite body color have become very popular, so that the volume of work concerned with these stones over the past few years has increased out of all proportion at the Gem Testing Laboratory of London. If this can be taken as an indication of current trends, then at long last the gem-buying public is finding out not only that black diamond is not another term for coal, but also that it is possible for diamonds to occur in superb shades of yellow, green, brown, pink, and blue (figure 1) that often make other colored gemstones seem quite dull in comparison.

It is hardly surprising, therefore, that as with other highly prized gemstones man has found it necessary to try to exert his influence on the poorer examples to "improve their quality," a practice that many gem merchants and customers find unacceptable. And it follows that the trade has requested the advice of gemologists to distinguish a natural from an artificially colored stone. Because of the great difficulties that can be involved, though, most gemologists have tended to leave the problem in the hands of the relatively few laboratories or individuals who have been able to specialize in the subject.

In some cases, the trader can himself determine the origin of color in a diamond fairly quickly and simply. Two methods involving the application of a diamond merchant's normal instrumentation are discussed below. In those more difficult cases where radiation treatment and subsequent annealing are involved, spectroscopy is the most useful technique. There are some cases, though, which will also be discussed below, in which even absorption spectra enhanced by cryogenic spectroscopy may not be able to prove conclusively the origin of color in a diamond. 


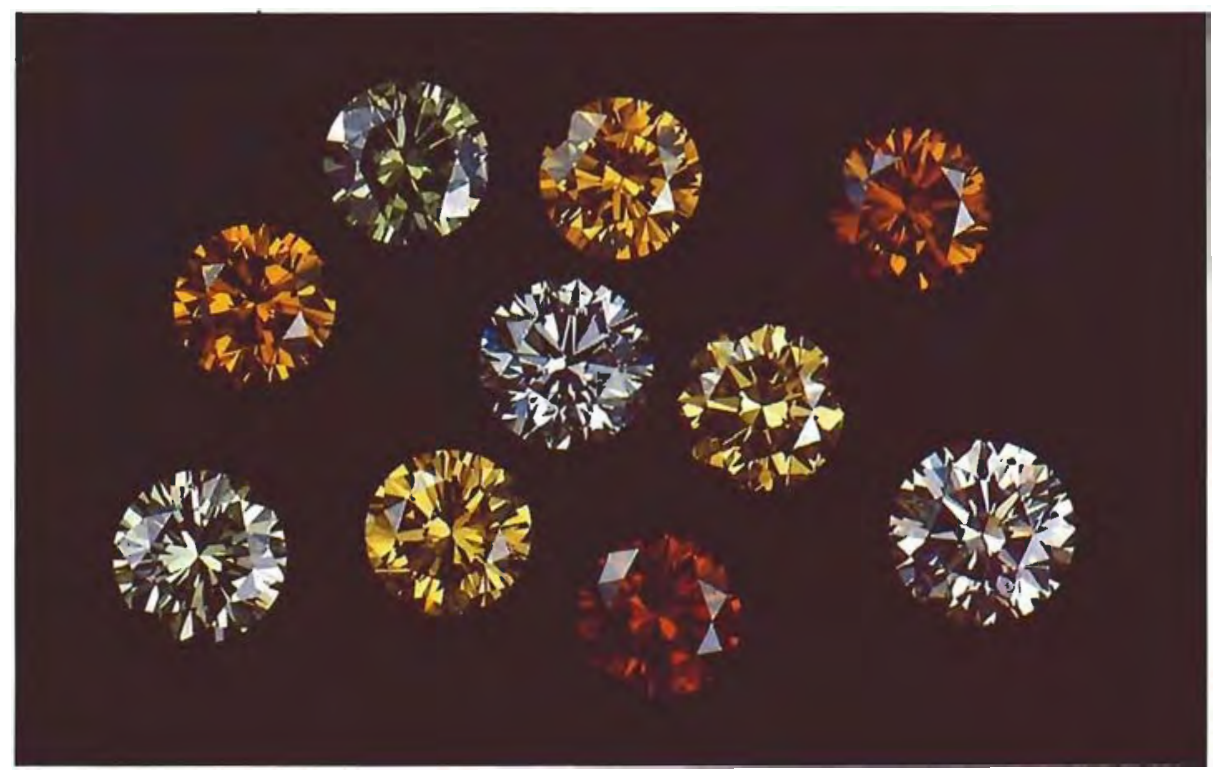

Figure 1. A suite of colored diamonds. The light pink $(0.68$ $\mathrm{ct})$ and light blue $(0.56 \mathrm{ct})$ stones are naturally colored. The yellow, orange, and green stones have been treated to improve color, although yellow and orange hues similar to those shown here are known to occur naturally. Photo by Tino Hammid.

\section{SOME SIMPLE METHODS OF DETERMINING WHETHER THE COLOR OF A DIAMOND IS NATURAL OR MAN INDUCED}

Virtually all diamond merchants possess some form of instrument to examine their stones at various magnifications-be it a hand lens or a microscope-and a source of ultraviolet radiation. With some experience, the merchant often can use the information gleaned from the stone with these instruments to determine whether the stone in question is naturally colored or has been treated.

In many cases, colored diamonds have very distinctive internal features. For example, the color in many natural brown stones is zoned (Kane, 1980), alternating between brown and colorless (not unlike the zoning seen in some sapphires). In other natural brown diamonds, the color zoning may appear to be angular. When some natural pink diamonds are examined with a lens, their color can be seen to be associated with the internal structure of the stone, which appears in the form of pink zoning on a colorless background (figure 2).

Although cyclotron-treated stones often display a form of zoning, natural zoning is usually associated with growth phenomena and, therefore, is aligned with the original crystal form. The zoning in a cyclotron-treated stone is associated with the shape of the cut stone; that is, it may appear as a color concentration at the culet, which looks something like an opened umbrella, or as a color concentration at the girdle (figure 3).
When natural type $\mathrm{II}_{\mathrm{B}}$ blue diamonds are bathed in short-wave ultraviolet radiation, they reveal characteristics that are distinctive of this type of diamond. Such stones either have a relatively weak fluorescence or are virtually inert, but they have a phosphorescence that is among the strongest observed in any type of diamond. They are also usually relatively clean internally and quite large. Very large pink diamonds are usually quite light in color and are type II stones, which allow short-wave ultraviolet radiation to pass, exposing any photographic paper on which such a stone may be placed.

Figure 2. The color in some naturally pink stones can be seen to be associated with their internal structure. Here it reveals itself on a colorless background as thin pink lines crossing crown facets. Magnified approximately $80 \times$.

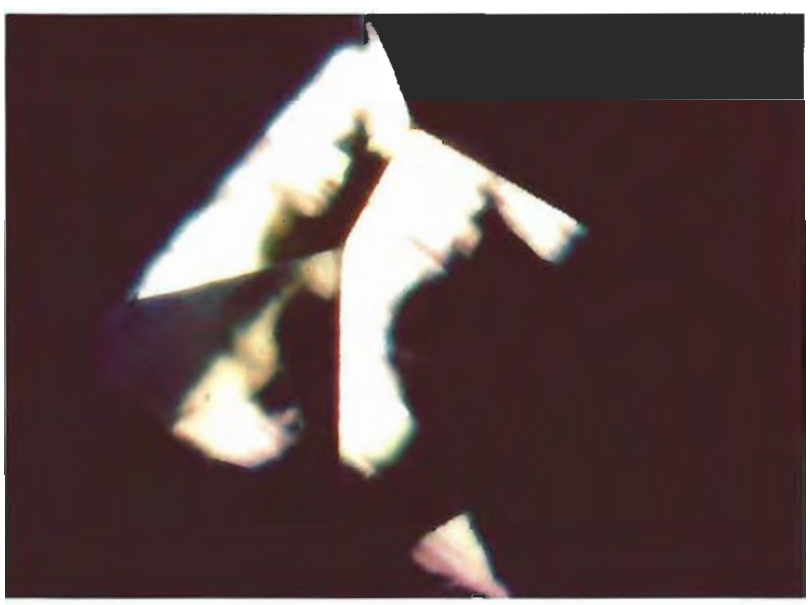



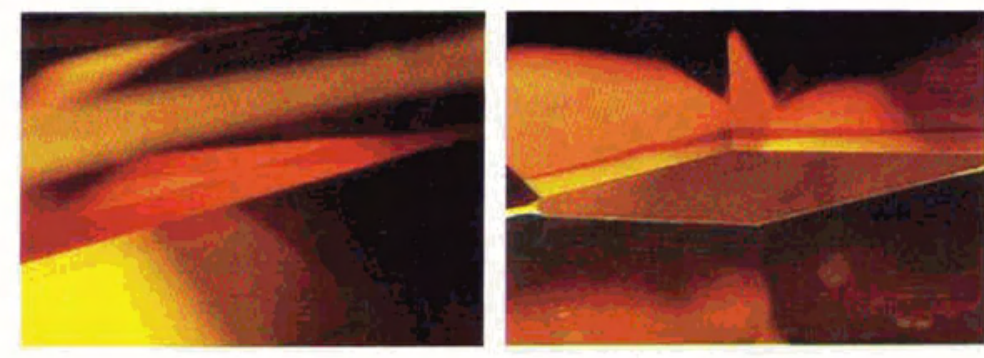

Figure 3. Zoning in a cyclotron-treated diamond appears as a concentration of color associated with the shape of facets of the cut stone. Left = color zoning paralleling the edges of the crown viewed through the pavilion, $40 \times$. Right $=$ color zoning paralleling the edge of the culet viewed through the table, $30 \times$. Photos by Robert E. Kane.

In the majority of cases, though, the internal features of the stone and its reaction to radiation are inadequate for the conclusive determination of the source of color. This is particularly true with diamonds that have been irradiated and then annealed to enhance or change the natural color by methods other than cyclotron treatment.

\section{DETERMINING THE SOURCE OF COLOR IN DIAMONDS THAT HAVE BEEN IRRADIATED AND SUBSEQUENTLY ANNEALED}

Man first learned that he could influence the color of diamond at the beginning of this century, when it was discovered that a green color could be induced by intimately exposing the stone to radium (Webster, 1972). However, stones treated in this manner retained radioactivity at levels that were easily detectable with a Geiger counter (a test that continues to be of importance in the examination of green diamonds today).

It was not until halfway through the century that it was discovered that a number of other forms of atomic bombardment could be used commercially to "treat" diamonds and that after subsequent annealing the irradiated green stones would alter once again to yellow and brown. These resulting colors were found to be strong and, in the main, deep penetrating and stable. From this point on, the task of identifying the nature of color in diamond became in some cases very difficult, because these irradiated stones do not retain any detectable radioactivity for a significant length of time, nor any other obvious indications of treatment. We were indeed fortunate that at this juncture Robert Crowningshield, director of gem identification of the GIA Gem Trade Laboratory in New York, came to the rescue of gemologists (Crowningshield, 1957). After observing the visible spectra of thousands of these irradiated and annealed diamonds, he determined the presence of an absorption band at $595(592)^{*} \mathrm{~nm}$ in almost every instance.

Since that time, determination of whether the color in a particular diamond is due to a process of nature or to man's intervention is usually based on the information obtained by the observation of that stone's visible spectrum. Over the years, however, other factors have come to light which make detection by this manner in some colored diamonds extremely difficult.

Spectrum Changes Induced by the Process of Irradiation and Annealing. A number of changes occur in the visible spectrum of a diamond during the process of irradiation and subsequent annealing. Knowledge of these changes is essential to the understanding of the source of color in a given stone.

Depending on the diamond and on the conditions of irradiation, during the initial irradiation process the stone usually turns some shade of green and a group of absorption bands are induced into the spectrum at varying strengths. These bands have been "numbered" by physicists and given the prefix GR (general radiation). The principal band and the one observed most often by gemologists is the GR1, at $741 \mathrm{~nm}$ (Clark and Walker, 1972). Upon annealing, at least two other absorption bands are induced. Typically, one of these is the sharp band at $595 \mathrm{~nm}$. Also apparent may be either the band at $503 \mathrm{~nm}$ or the one at $496 \mathrm{~nm}$, and very often both are seen. Any naturally occurring absorption that was evident in the spectrum prior to irradiation, such as the band at $415 \mathrm{~nm}$, remains unaffected (figure 4).

The relative strengths of the induced bands are affected by the annealing temperature (Collins, 1978). As the temperature increases, the GR1 reduces in strength until it disappears at around $800^{\circ} \mathrm{C}$. The $595 \mathrm{~nm}$ band increases to its maximum at around $800^{\circ} \mathrm{C}$, but above this temperature the 595 weakens until it disappears at around

- This sharp absorption band is observed between 592 and $595 \mathrm{~nm}$. The tradition in American gemology has been to refer to this feature as the $592 \mathrm{~nm}$ absorption center. 
$1000^{\circ} \mathrm{C}$. The band at $503 \mathrm{~nm}$, which has the greatest effect on the color of the irradiated diamond, remains comparatively unaffected at least until several hundred degrees beyond the position where the band at $595 \mathrm{~nm}$ "anneals out."

It follows then that it is possible to produce an irradiated diamond with a strong yellow color in which the only indication of radiation treatment may be the bands at 503 and $496 \mathrm{~nm}$. Inasmuch as these two bands can and very often do occur naturally, identification of treatment in such stones may be very difficult.

Another way in which the $595 \mathrm{~nm}$ band is temperature dependent is sometimes evident from its behavior when the spectrum is being examined. If the stone is heated much above room temperature, very often the band will broaden and, if it is weak to start with, the band will become undetectable with the hand spectroscope until the stone has cooled. This has led gemologists to seek methods by which they can keep the stone cool while under examination (see, for example, Hofer and Manson, 1981).

Low-Temperature Spectroscopy. The most successful cooling method to date entails the use of liquid nitrogen or the gas produced from it. The method used at the London Gem Testing Laboratory ensures a temperature in the region of

Figure 4. Absorption spectrum recorded at about $-160^{\circ} \mathrm{C}$ for a yellow diamond that has been irradiated and then annealed. The 503, 496, and $415 \mathrm{~nm}$ lines have been labeled by physicists as $\mathrm{H3}, \mathrm{H} 4$, and $\mathrm{N} 3$, respectively. The small peaks around $741 \mathrm{~nm}$ are part of the GR system.

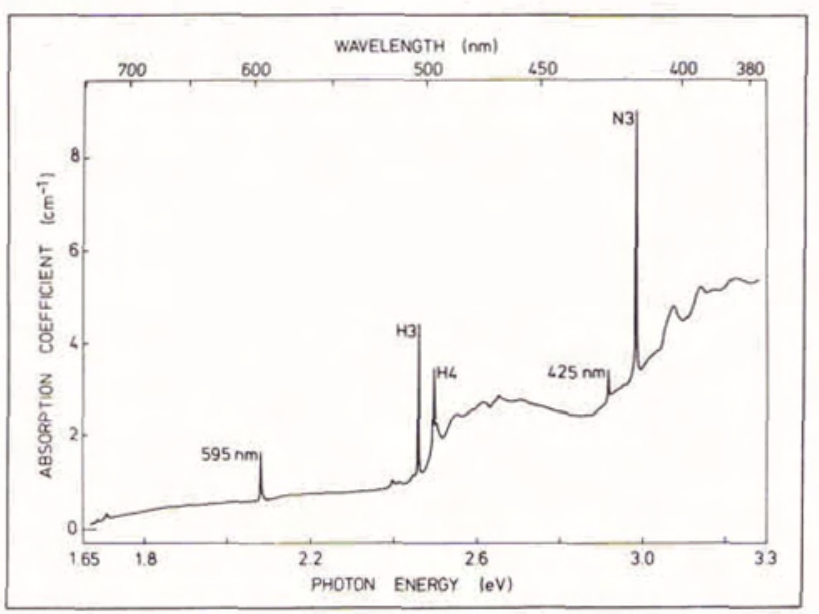

$-160^{\circ} \mathrm{C}$ for the period of examination. This temperature is reached gradually over approximately a quarter of an hour. The stone is first set in soft metal and then placed into a double-walled glass vessel. The space between the two walls is evacuated in a manner similar to a thermos flask. The nitrogen gas is then allowed to pass through the vessel and thus cools the stone (figure 5).

The size of the vessel used depends on the size of the stone. For the examination, the vessel is set in the center of an optical bench with the light source at one end and the spectroscope at the other.

This system not only ensures that if the band at $595 \mathrm{~nm}$ is present, it will not disappear, but it also makes the band sharper and therefore easier to see when it is at its weakest, say, after the stone has been annealed to $900^{\circ} \mathrm{C}$. In fact, this cooling of the stone sharpens all the radiationrelated bands to such an extent that observation becomes quite easy. This point is brought home when one realizes that with the stone held at a low temperature it is possible to observe the GR system, with its main band at $741 \mathrm{~nm}$, using the hand spectroscope (Scarratt, 1979). While this method of observation has in many respects made the task of color identification easier, it has also raised a number of other questions. Of particular importance is the discovery in some cooled nat-

Figure 5. One of the glass vessels used to hold a colored diamond at about $-160^{\circ} \mathrm{C}$, at which temperature any absorption lines that may be present in the stone's visible spectrum are seen at their sharpest. The stone is held in soft metal in the center; the nitrogen gas enters via an insulated pipe on the left, flows over the stone, and exhausts through the metal tube on the right.

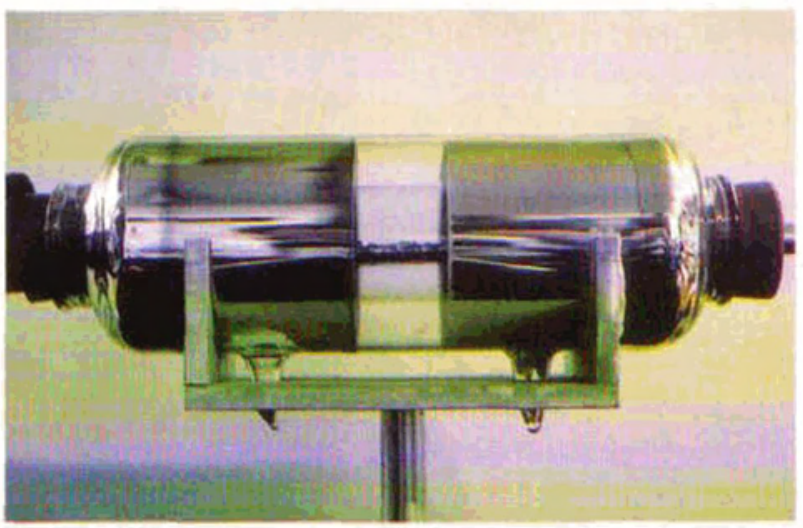


ural stones of absorption bands formerly believed to appear only in artificially colored stones.

\section{NATURAL IRRADIATION IN COLORED DIAMONDS}

B. W. Anderson first noted the $595 \mathrm{~nm}$ absorption band in a colored diamond in 1943 (Crowningshield, 1957). This was not in the spectrum of a treated stone but in that of a natural uncut brown stone from the Central African Republic (figure 6). This stone was one of a pair given to Mr. Anderson. We have since been able to examine both diamonds at low temperatures, and found not only that the $595 \mathrm{~nm}$ band was present in the spectrum of both stones but also that the GR system was still present in the one that did not show the $595 \mathrm{~nm}$ band at room temperature. When it was determined that the color of these stones was confined to the surface (figure 7) and would, therefore, be removed with faceting, gemologists tended to ignore this natural occurrence of the $595 \mathrm{~nm}$ line. However, these stones do give us some background information that is of great help in our understanding of colored diamonds.

Specifically, the presence of the GR system tells us that the brown surface coloration in this pair is due to natural radiation. We also know that these stones have been subject to an annealing process, both because of the presence of the 503

Figure 6. Absorption spectrum recorded at about $-160^{\circ} \mathrm{C}$ for an uncut brown diamond from the Central African Republic, with color confined to the surface (see figure 7) because of natural radiation damage and annealing. The GR1 and $595 \mathrm{~nm}$ lines are clearly present.

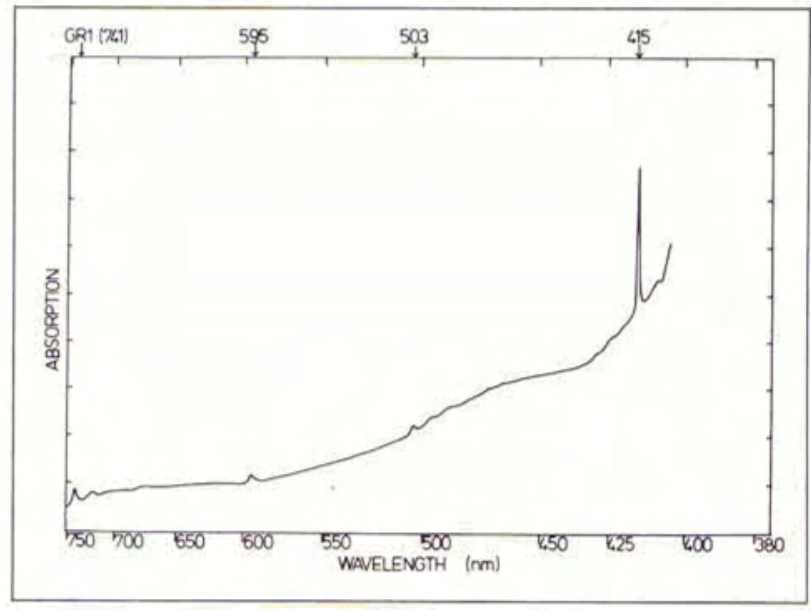

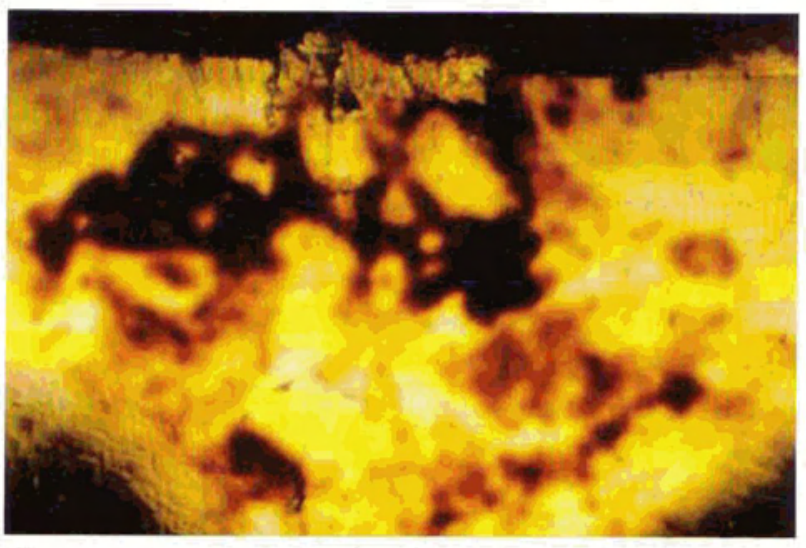

Figure 7. Brown natural radiation "staining" on the surface of a diamond crystal from the Central African Republic. Magnified approximately $50 \times$.

and $595 \mathrm{~nm}$ bands and because of the brown rather than green coloration (Mendelssohn et al., 1979). This information helped us a few years ago in our understanding of one particular faceted stone, with a fluorescent green body color. All naturally colored diamonds of this type reveal very similar spectra: that is, the presence of the 503 , probably the 496, and certainly the $415 \mathrm{~nm}$ bands. But when the spectrum of this stone was examined at $-160^{\circ} \mathrm{C}$ (figure 8), the $595 \mathrm{~nm}$ line was also seen to be present. In fact, the spectrum was indistinguishable from that of a normal

Figure 8. Absorption spectrum recorded at about $-160^{\circ} \mathrm{C}$ for a naturally colored, fluorescent-green faceted diamond. The spectrum is indistinguishable from that of a normal treated yellow stone (see figure 4).

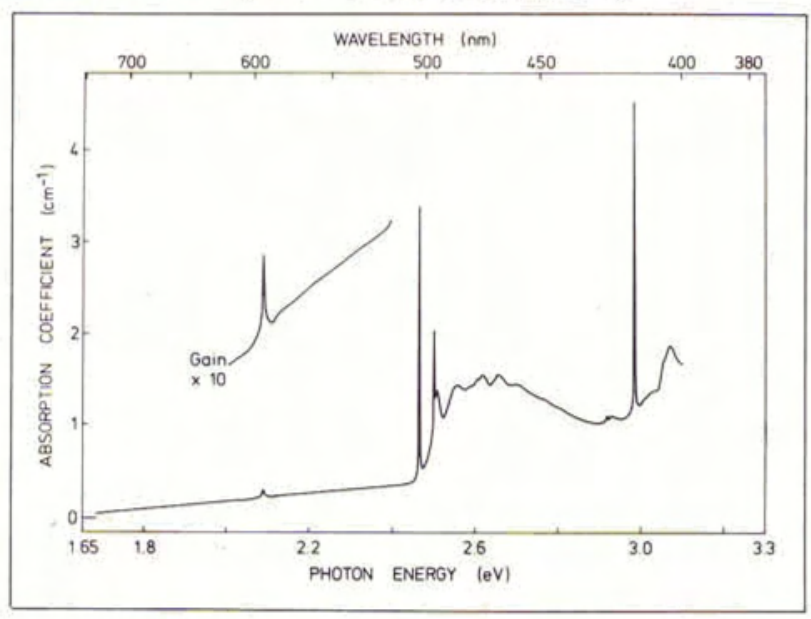


treated yellow stone, and yet we know from the stone's history that the color must be natural.

We know that the lines at 503 and $496 \mathrm{~nm}$ can be induced by the annealing of a stone that has been irradiated, so we should not have been too surprised at recording the $595 \mathrm{~nm}$ band in this type of stone. To our knowledge, though, it was the first time it had been seen in a natural faceted stone.

At least this particular stone revealed evidence of natural radiation damage and annealing in the form of brown radiation stains on an uncut portion of the girdle (figure 9), but the fact that the $595 \mathrm{~nm}$ band has been observed in this stone makes the identification of the origin of color in these fluorescent green stones very difficult.

Of late, we have also been observing the GR system in the spectrum of very large, naturally colored, brown type II stones. Because of the increased popularity of colored diamonds, any diamond with a definite body color, almost regardless of quality, is being sorted out as a possible fancy stone. As a result, in addition to the attractive canary yellow stones that have been traditionally sought after (figure 10), we are seeing many more type $I_{B}$ stones which, not many years ago, would have been rejected by the trade as undesirable. Many of these stones are easily recognizable because of their characteristic large areas of cloud-type inclusions, and because their yellow body colors usually have some other component present, that is, green or brown.

In the past, color identification in this type of stone presented no problem for the gemologist, because normally the true canary yellow (like any other natural type $\mathrm{I}_{\mathrm{B}}$ diamond) shows no sharp changes in transmission in the visible spectrum

Figure 9. Nalural radiation "staining" on an unpolished portion of the girdle of the stone referred to in figure 8. Magnified approx. 70x.

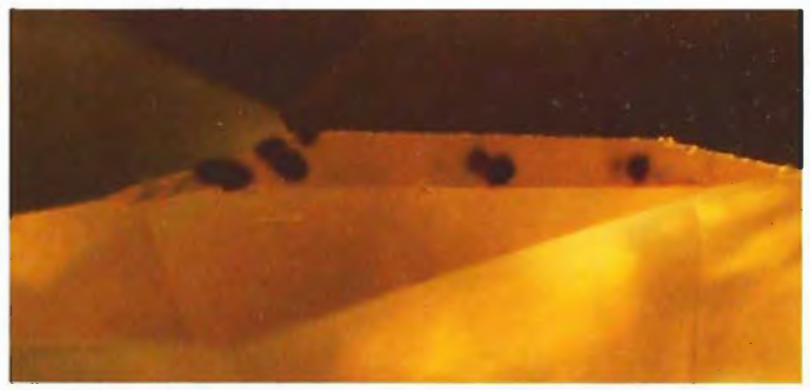

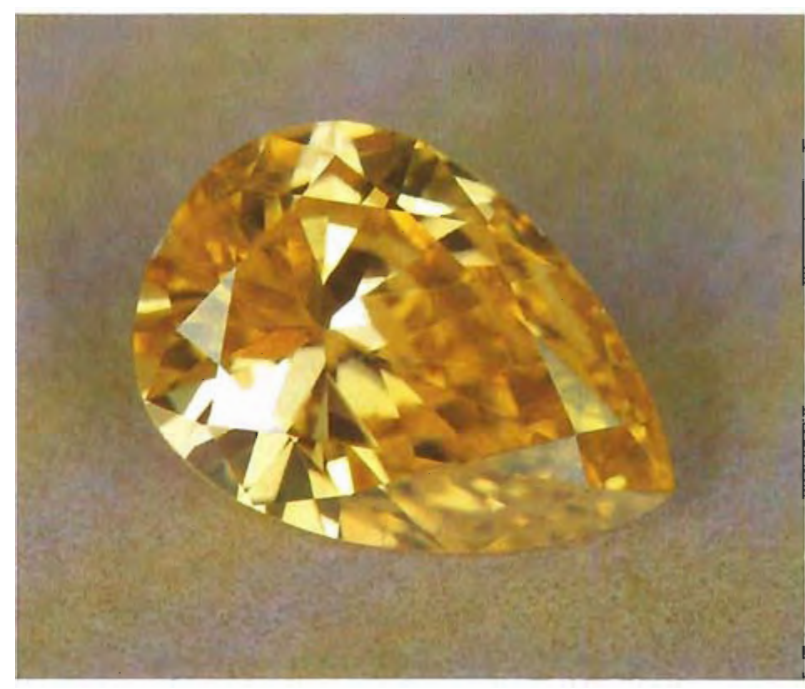

Figure 10. Naturally colored canary yellow diamond, $0.63 \mathrm{ct}$. Photo by Tino Hammid.

at room temperature. The color is due to the gradual absorption of wavelengths that are shorter than $550 \mathrm{~nm}$.

The appearance in the lab of more of these stones and the advent of low-temperature spectroscopy caused us considerable worry a year or so ago when, in addition to the normal gradual absorption of the shorter wavelengths, we noted at low temperatures the occurrence of the radiation-related peak at $637 \mathrm{~nm}$ and sometimes the $503 \mathrm{~nm}$ band (figure 11).

Figure 11. Absorption spectrum recorded at about $-160^{\circ} \mathrm{C}$ for a naturally colored yellow type $1_{\mathrm{B}}$ diamond, showing the peaks at 637 and $503 \mathrm{~nm}$ and the typical $1_{\mathrm{B}}$ type absorption of wavelengths shorter than $550 \mathrm{~nm}$.

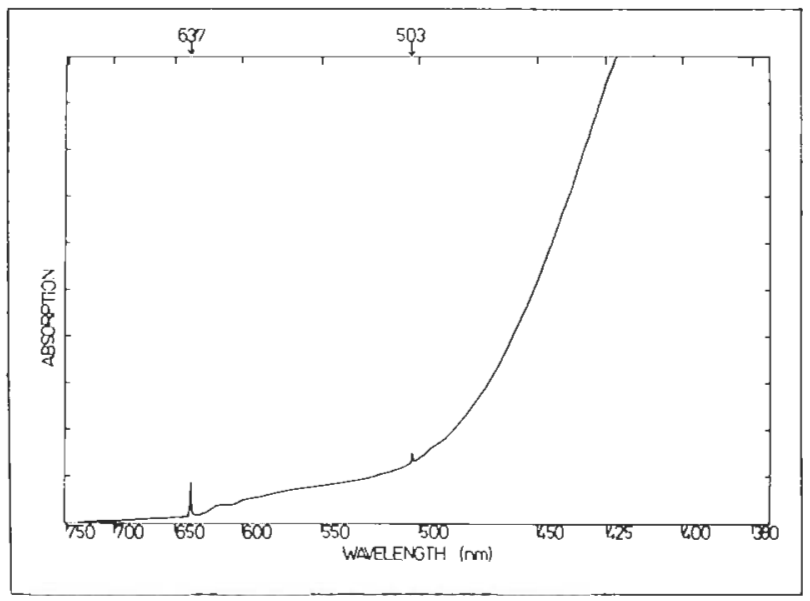


Researchers have found that the $637 \mathrm{~nm}$ band occurs primarily in diamonds that contain a high percentage of the nitrogen impurity in isolated substitutional form, that is, in type $\mathrm{I}_{\mathrm{B}}$ diamonds. It has been proved experimentally that irradiation and subsequent annealing induce the $637 \mathrm{~nm}$ band in synthetic type $I_{B}$ diamonds, during which process the color of the stone is altered from its original yellow to pink (Davies, 1977). In fact, the 637 $\mathrm{nm}$ band had previously been reported only in treated diamonds, particularly in treated pinks (Liddicoat, 1969), and so the diagnostic value of this line when seen at low temperatures in yellow type $\mathrm{I}_{\mathrm{B}}$ stones had to be determined.

After recording the absorption curve in the nine stones of this type in which we had observed the $637 \mathrm{~nm}$ band, we noted that in each case the line was extremely weak, and it soon became apparent that the obvious cause of the body color was the gradual absorption of the shorter wavelengths. This being a natural phenomenon, we decided that if these stones had been artificially subjected to radiation and annealing it could only have been in minimal amounts and as such had no effect on the color of the stone. In fact, our view was that this was yet another case of the natural occurrence of a radiation-related peak and that under these circumstances it should be reported accordingly.

\section{IN CONCLUSION}

I emphasize that the foregoing problems affect only a small percentage of colored diamonds. Certainly, as discussed above, reliable methods for the detection of cyclotron-treated diamonds are now readily available to diamond merchant and laboratory gemologist alike. And in the "vast ma- jority" of cases where a yellow diamond has been irradiated and annealed by man, it is virtually always possible to recognize this fact with the adept use of the hand spectroscope in conjunction with a cold light source.

However, I can foresee a time when, at least with some of this small percentage of colored diamonds, the methods currently available will not be adequate to determine whether the color is caused by man's interference. It is likely that the problem of differentiating between irradiation by man and irradiation by nature will continue to arise and with even greater frequency.

\section{REFERENCES}

Clark C.D., Walker J. (1972) Optical measurements of the GR1 centre in diamond. Diamond Research, pp. 2-5.

Collins A.T. (1978) Investigating artificially coloured diamonds. Nature, Vol. 273, No. 5664, pp. 654-655.

Crowningshield G.R. (1957) Spectroscopic recognition of yellow bombarded diamonds and bibliography of diamond treatment. Gems e) Gemology, Vol. 9, No. 4, pp. 99-104.

Davies G. (1977) Optical properties of diamond. Chemistry and Physics of Carbon, Vol. 13, Marcel Dekker, lne., New York, NY

Hofer S.C., Manson D.V. (1981) Cryogenics, an aid to gemstone testing. Gems e) Gemology, Vol. 17, No. 3, pp. $143-149$.

Kane R.E. (1980) The elusive nature of graining in gem-quality diamonds. Gems (4) Gemology, Vol. 16, No. 9, pp. 294-314.

Liddicoat R.T. Ir. (1969) Handbook of Gem Identification. Gemological Institute of America, Los Angeles, CA.

Mendelssohn M.J., Milledge M.J., Vance E.R., Nave E., Woods P.A. (1979) International radioactive halos in diamond. Diamond Research, pp. 31-36.

Scarratt K. (1979) Investigating the visible spectra of coloured diamonds. Jounnal of Gemmology, Vol. 16, No. 7, pp. $433-447$.

Webster R. (1972) Gems, Their Sources, Description and Identification, 2nd ed. Butterworth and Co., Ltd., London. 